\title{
Innovative Activity as a Factor of Mining Region Sustainable Development
}

\author{
Igor Lyamkin ${ }^{1}$, Zhanna Ozderbiyeva ${ }^{1}$, Olga Shershneva $^{1,{ }^{*},}$ and Alena Khirnaya $^{1}$ \\ ${ }^{1}$ Kemerovo institute (branch) of Plekhanov Russian University of Economics, Department of \\ economic security, accounting and auditing, 650992 Kuznetsky pr. 39, Kemerovo, Russia
}

\begin{abstract}
The article considers innovative processes and innovative activity of subjects as a factor of sustainable development. Factors putting back and facilitating the innovative processes in the low-tech sector of the economy are singled out. It is substantiated that the transition to an innovative economy raises the requirements for the workforce quality, and, consequently, the organization of labor. This involves raising the level of labor remuneration to the world standards. To ensure the sustainable development of the region, an optimal competitive environment is needed. Therefore, the relationship between the innovative development of the Russian economy and the level of market competition has been revealed. Measures for increasing innovative activity in industrial regions are proposed.
\end{abstract}

\section{Introduction}

Innovative processes originate in individual branches of science, and are completed in the sphere of production, causing its progressive, qualitatively new changes. The country's competitiveness is assessed depending on the development of these processes.

The development of an innovative economy as a modern vector of its development is impossible without the evolution of high-tech and knowledge-intensive industries. According to OECD classification there are the following levels: high-tech, medium hightech, medium low-tech and low-tech.

Low-tech industries are the link between the high-tech sector and the consumer, because the high-tech industries accumulate and generate the bulk of knowledge, and this sector does not directly interact with the end user. The high-tech sector as a whole improves the economic situation in the market, while the low-tech sector forms the basis of the economy and provides the main part of employment, as well as added value. This explains why the share of the low-tech sector remains high. This sector includes: building, extracting branches, trade, food industry, etc.

\section{Materials and Methods}

The classification of industries based on the technology level according to OECD (and for comparison in Germany) is presented in Table 1. For example, in Germany, industries with R\&D expenditures of less than $2.5 \%$ are considered to be low-tech, but according to OECD classification - medium high-tech levels.

\footnotetext{
* Corresponding author: daizy77@mail.ru
} 
Table 1. Classification of industries based on the technology level.

\begin{tabular}{|l|c|c|}
\hline Industries & Germany, \% & OECD (since 2009) \\
\hline High-tech level & $>7$ & $>7$ \\
\hline Medium high-tech level & $2.5-7$ & $2-7$ \\
\hline Medium low-tech level & less 2.5 & $0.5-2$ \\
\hline Low-tech level & & less 0.5 \\
\hline
\end{tabular}

Another important difference between these sectors is their participation in R \& D. So, in the low-tech sector the researches are conducted in a very small amount, whereas in the high-tech sector they occupy a key place in innovations. Let us consider factors that influence innovation in the low-tech sector.

In Russia the share of high-tech industries in GDP has a tendency to grow and is characterized by uneven dynamics. The data are presented in Table 2.

Table 2. The share of high-tech sector in Russia's GDP [1].

\begin{tabular}{|l|c|c|c|c|c|c|c|}
\hline & $\mathbf{2 0 1 1}$ & $\mathbf{2 0 1 2}$ & $\mathbf{2 0 1 3}$ & $\mathbf{2 0 1 4}$ & $\mathbf{2 0 1 5}$ & $\mathbf{2 0 1 6}$ & $\mathbf{2 0 1 7}$ \\
\hline $\begin{array}{l}\text { The share in } \\
\text { GDP, } \%\end{array}$ & 19.7 & 20.3 & 21.1 & 21.8 & 21.3 & 22.0 & 22.1 \\
\hline
\end{tabular}

The search for reasons hindering innovative processes in the low-tech sector made it possible to identify a number of factors. The significant influence is made by such factors as: lack of financial resources, low innovative activity, and underdevelopment of marketing research system, lack or absence of personnel with the necessary skills.

The following factors may enhance the innovations in the low-tech sector: the launch of new products in the market and their high importance for the target consumers, the emergence of new competitors. Another factor to be highlighted is the steady innovations researched by the scientists of the Georgia International Business Institute and the Copenhagen Business School. [2]

Sustainable innovations take into account the environmental, social consequences and interests of future generations. They offer new perspectives for enterprises development, but they are associated with the need for certain costs, organizational efforts and competencies for solving the problems. The calculation of such innovations is associated with the importance of combining such traditional tasks as maximizing profits and increasing output, while maintaining social and environmental parameters. Recently, consumers have been increasingly demanding goods and services of environmentally sustainable production. The latter is understood as production with the help of ecologically harmless and efficient processes that allow saving resources, reduce harmful impact on the environment and improve the safety and health conditions for all agents of economic relations. [2-5]

\section{Results and Discussion}

To implement the sustainable innovations, it is necessary to reconsider the requirements not only for the organization of work and coordination of management functions, but also the work of human resources management, research and development departments and others.

The factors of sustainable innovation are considered by scientists to be the potential for generating innovation and the prospect of its development. In the center of these factors, we can see human potential, the ability of a person to find, master and use external knowledge.

Along with the development of innovative processes, the information economy is being developed, which increases the requirements for the workforce quality and leads to regular changes in the organization of labor. However, the development of the information 
economy leads to a polarization of the labor market specific for industrialized countries. Against the decrease of workplaces for middle-level employees, two types of jobs are being formed: properly paid managerial jobs that require high qualification level and low-paid jobs for workers with low level of skills. [6]

Accordingly, a new employee type must have independence and autonomy in making production decisions, and have the skills of related professions. On the one hand, this allows private enterprises to reduce the wage costs, on the other hand to pay high salary to those workers whose work they are most interested in.

According to the forecasts of experts in the EU countries employment in information technology field will increase from 1.9 million people in 2010 to 2.2 million in 2020. [7] This characterizes the dynamic development of the labor market, but also reveals some contradictions. On the one hand, there is an expansion of employment and wage growth, on the other hand, intensification of labor and competition in the labor market intensify.

Taking into account the subject of innovation, the following types are distinguished: technical and technological innovations; organizational innovations; managerial innovations; economic innovations; legal innovations; ecological innovations; social innovations. In modern conditions, social innovations are relevant. They are manifested in the form of activating the human factor through the development and implementation of a system for improving personnel policy; system of professional training and improvement of employees; systems of social and professional adaptation of newly recruited persons; system of remuneration and evaluation of labor performance. The importance of social innovations for the successful development of the economy is obvious, since it is due to the development of innovative processes in production, which can change not only the structure of the economy, but also affect the labor market. The emergence of new specialties, an increase in the requirements for the level of training suggests that job hopers should have qualitatively new knowledge and skills.

One of the state priorities in modern conditions is the modernization of the Russian economy, which is impossible without the development of high technology and the active use of intellectual resources. But in order to develop the intellectual potential of the country, it is necessary to change dramatically the concept of wage labor assessment. According to experts, the wage systems existing at many enterprises no longer meet modern requirements. They do not have sufficient motivational effect; they do not contribute to increasing labor productivity. The share of labor costs in total production costs of enterprises is at the level of $15-20 \%$.

Of particular concern is the fact that Russia is in $5-6$ times behind the European Union in terms of salaries and social expenditures. In modern conditions, the annual doubling of the capital of Russian billionaires is an indicator of the scale of underpayment of wage workers and taxes to the state, illicit export of capital and the appropriation of commodity rent. Over the past 15 years, total revenues of billionaires have increased more than 30 times. A specific trend in the development of innovative processes is the steady understating the level of wages.

The transition to the decent wages requires a gradual increase in the purchasing power of the minimum wage rate established by the state. According to OECD data for 2015, in comparison with other countries, Russia is the last in terms of the minimum wage $-\$ 97$. For reference, in Australia, the minimum wage rate is $\$ 1780$, Belgium $-\$ 1,744$, Germany $-\$ 2,065$, Luxembourg $-\$ 1942$. Since January 1, 2018, the minimum wage rate has been increased to 9489 rubles, and has grown to $85 \%$ of the subsistence minimum of the employable population. We returned to 2009 by this indicator when it was $84.2 \%$. For comparison, in 2015 there was $61 \%$. If Russia is aimed at development, it is necessary to reform the wage system, namely, to pay the same as in Europe, with an adjustment to labor productivity. 
Sectoral and regional differentiation in labor remuneration remains in the Russian economy. For example, in Kuzbass the growth of wages can be called as a positive trend, so if in 2007 it was 19.252 rubles in the coal industry, then by January, 2018 it increased to 52.800 rubles. Nevertheless, the salary in the coal industry is not the same, its level fluctuates. Undoubtedly, the work is fraught with risks, its complexity and therefore the salary should be sufficient for a decent reproduction of labor force.

Among the factors hampering the development of innovative processes in the economy there is such factor as low innovative activity, which has the largest share among other factors. For example, the concept of sustainable development as a process of long-term balanced improvement of the quality of economic, ecological and social spheres of life, which emerged in the second half of the XX century, determines the importance of the innovative activity of market actors. However, at present, innovative activity in the Russian economy remains at a low level. Thus, in the ranking of the global innovation index, Cornell University and the international business school INSEAD, in 2017the Russian Federation ranked the 45 th out of 127 positions [8]. Therefore, it is required to find the ways to intensify innovative processes and to identify factors of innovative activity of economic entities. The most important factor is the effectiveness of "human capital". The twentieth century was called the scientific age of "human capital" [9]. Nowadays, the role of human capital only increases. Therefore, the sustainable development of the region is impossible without improving the quality of human capital. The transformation of human potential into capital takes place in the labor market.

The development of effective human capital for ensuring the sustainable development of the region requires an optimal competitive environment. Taking the above into account, an urgent problem is the study of the relationship between the innovative development of the Russian economy and the level of market competition. At present, there is no single approach to understanding the relationship between the competitive and innovative aspects of the activities of market entities. Therefore, we made an attempt to check the existence in the economy of Russian regions the nonlinear relationship between competition and innovation (interconnection in the form of an inverted U) established by F. Scherer on the basis of research of the world's largest companies [9].

In this paper, based on the information available, a modified Lerner index is used to assess the level of competition. It is defined as the unit profit of organizations, that is, as the ratio of the financial result of organizations' activities to their revenues. The growth of this indicator testifies a reduction in the level of competition, decrease-growth in the level of market competition [10].

To measure the intensity of innovation, we use the index of innovative activity of organizations calculated by the Federal Service for State Statistics in terms of economic activities as the share of innovative goods, works and services in the total volume of goods, works and services. The dynamics of this indicator, in our opinion, has sufficient reliability in order to form an adequate model for the solution of the stated task.

The average values of unit profit of organizations in the Russian Federation and their innovative activity for 2012-2016 by the types of economic activity were calculated by the authors using the data of the Federal State Statistics Service of the Russian Federation [1] and are presented in Table 5 .

To assess the nature of the relationship between the average value of unit profit and the average value of innovation activity of organizations by economic activity with the help of Microsoft Excel we obtained the equation of the approximating curve with the highest value of the reliability of the approximation R2 (0.41):

$$
\begin{aligned}
& y=-280.85 x^{2}+67 . / 42 x+2.7341, \text { where } \\
& y-\text { innovative activity of organizations; } \\
& x-\text { unit profit of organizations. }
\end{aligned}
$$


Table 3. The average values of unit profit and innovative activity of organizations of the Russian Federation for 2012-2016 by the type of economic activities

\begin{tabular}{|l|c|c|}
\hline \multicolumn{1}{|c|}{ Type of economic activity } & Unit profit & $\begin{array}{c}\text { Innovative } \\
\text { activity, \% }\end{array}$ \\
\hline Extraction of mineral resources & 0.199 & 4.686 \\
\hline Food production. including beverage and tobacco & 0.043 & 3.511 \\
\hline Textile and clothing manufacture & 0.028 & 2.083 \\
\hline $\begin{array}{l}\text { Leather manufacturing. leather products and } \\
\text { shoemaking }\end{array}$ & -0.014 & 1.633 \\
\hline Wood processing and production of wood ware & -0.030 & 2.448 \\
\hline $\begin{array}{l}\text { Cellulose and paper production; publishing and } \\
\text { polygraphic production }\end{array}$ & 0.051 & 3.665 \\
\hline Coke industry and oil-product & 0.091 & 7.549 \\
\hline Chemical production & 0.091 & 7.549 \\
\hline Manufacture of rubber and plastic products & 0.032 & 7.701 \\
\hline $\begin{array}{l}\text { Manufacture of other non-metallic mineral } \\
\text { products }\end{array}$ & 0.023 & 3.174 \\
\hline $\begin{array}{l}\text { Metallurgical production and production of } \\
\text { finished metal products }\end{array}$ & 0.057 & 5.899 \\
\hline Machinery and equipment production & 0.025 & 4.548 \\
\hline $\begin{array}{l}\text { Production of electric equipment. electronic and } \\
\text { optical equipment }\end{array}$ & 0.059 & 9.420 \\
\hline $\begin{array}{l}\text { Production and distribution of electrical energy. } \\
\text { gas and water }\end{array}$ & 0.012 & 0.513 \\
\hline
\end{tabular}

The relationship between the average value of unit profit and the average value of innovation activity of organizations by types of economic activity, as well as the approximating curve are shown in Figure 1.

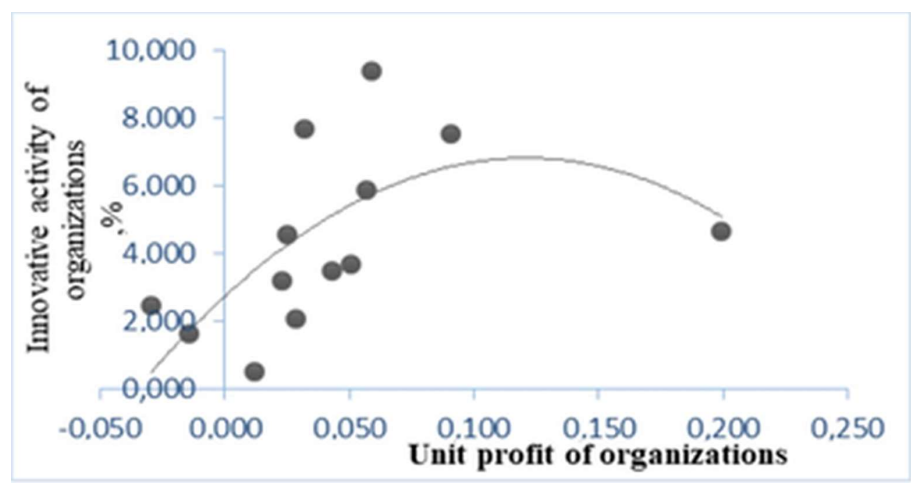

Fig.1. The dependence between the average value of unit profit and the average value of innovative activity of organizations.

The results obtained are basically consistent with the conclusions made by F. Scherer about the existence of a nonlinear relationship between competition and innovation. The shape of the approximating curve corresponds to an inverted $U$ and indicates: 
- the growth of innovative activity of organizations as the level of competition declines with the value of unit profit within the range of -0.03-0.125.

- the reduction of innovative activity of organizations with further reduction of the level of competition (the value of unit profit is more than 0.125 ).

Thus, empirical evidence proves the existence of a nonlinear connection in the form of an inverted $U$ between the level of competition and the magnitude of innovative activity of enterprises in the Russian economy. The theoretical justification of the identified empirical relationships can be realized using the effects of opportunities and incentives for innovation.

The effect of innovative opportunities is that as the level of competition increases, opportunities for innovation are reduced. This is due to the reduction in the size of enterprises, and, consequently, the reduction of their material, labor and financial resources for innovation. Thus, the effect of innovative opportunities as the level of competition increases leads to a reduction in innovative activity in the economic system.

The effect of innovation incentives is related to the impact of the competitive environment on incentives for innovation. Proceeding from the premise that the main stimulus of innovative activity is obtaining a competitive advantage, one can come to the conclusion that with an increase in the level of competition incentives for innovation are increasing. As a result, the effect of innovation incentives as competition increases leads to an increase in innovative activity in the economic system.

Thus, the effects of opportunities and incentives of innovation act in opposite directions. The final result of their influence on innovative activity depends on the state of the competitive environment. So, in conditions of pure monopoly, innovative activity in the economic system due to lack of incentives for innovation is zero. As the level of competition increases due to the emergence and strengthening of the incentive effect of innovations, innovative activity increases. Its growth continues until the effect of the opportunities effect overrides the effect of the incentive effect of innovations, after which the trend of development of innovation activity changes to the opposite. In the conditions of perfect competition, it again becomes equal to zero because of the lack of opportunities for innovation.

\section{Conclusion}

In order to achieve sustainable development of the region, it is necessary to take into account the factors that hinder and facilitate the activation of innovative processes in the low-tech sector of the economy. At the same time, effective innovative development cannot be discussed if the main producer of new knowledge, technologies and products - the employee -lives on the age of physical survival, or at best, at the low-quality level of satisfaction of limited needs.

At the macro level, it is possible to identify measures to overcome the low assessment of labor. First, it is advisable to raise the minimum wages rate, social pensions and the amount of the subsistence minimum in several times. Secondly, to exempt from taxation the income which is two times below the subsistence level for each family member and restore a progressive scale of taxation. Thirdly, taking into account that in the structure of Russia's GDP, the share of labor payment is $46.7 \%$ (2016), and in the West $-60-70 \%$, it is necessary to make up wages in the structure of the product at least $60 \%$. Worthy wages can stimulate an employee to work with a new quality, and this is a significant factor in the innovation process.

To obtain a positive result of the government policy aimed at the formation of an innovative model of the region's economic development, it is expedient: to identify the nature of the relationship between competition and the magnitude of innovative activity of 
enterprises for definite segment of state regulation; the development of measures to change the level of competition in the direction necessary for increasing the innovative activity of economic entities for a particular regulated segment.

\section{References}

1. Rosstat, Macroeconomic Statistics (Rosstat, Moscow, 2017)

2. I. Ketata, W. Sofka, C. Grimpe, R\&D Management, 45:1, 60-75 (2015)

3. A. V. Myaskov, S. M. Popov, Economics and Innovation Management, 1, 16-24 (2018) DOI: 10.26730/2587-5574-2018-1-16-24

4. A. N. Tokarev, Economics and Innovation Management, 1, 25-35 (2018) DOI: 10.26730/2587-5574-2018-1-25-35

5. V. G. Mikhailov, Ya. S. Mikhailova, Economics and Innovation Management, 3, 73-79 (2017) DOI: 10.26730/2587-5574-2017-3-73-79

6. N. Colin, A. Landier, P. Mohnen, A. Perrot, Les notes du Conseil d'analyse econ., 26, $11(2015)$

7. U. Holtgrewe, New technology, work employment, 29:1, 16 (2014)

8. The Global Innovation Index 2017 rankings (GANE, Washington, 2018)

9. C. Goldin, Katz L., American Economic Review, LVII, 524 - 531 (1967)

10. Z. Jurkasová, M. Cehlár, S. Khouri, Int. Conf. on Engin. Sci. and Prod. Man., ESPM, 409-412 (2015) 